\title{
Validation of the Family Stability Questionnaire in married couples: a confirmatory factor analysis
}

Zahra Pourmovahed ${ }^{1}$, Hassan Zareei Mahmoodabadi ${ }^{2}$, Seyed Mojtaba Yassini Ardekani ${ }^{3}$, Hossein Fallahzadeh ${ }^{4}$, Hossein Tavangar ${ }^{5}$, Seyed Saied Mazloomy Mahmoodabad ${ }^{6}$

${ }^{1}$ Ph.D. Candidate, Department of Health Education and Promotion, Social Determinants of Health Research Center, School of Public Health, Shahid Sadoughi University of Medical Sciences, Yazd, Iran

${ }^{2}$ Ph.D. of Psychology, Assistant Professor, Department of Education and Psychology, Yazd University, Yazd, Iran

${ }^{3}$ Psychiatrist, MD, Professor, Department of Psychology, Research Center of Addiction and Behavioral Sciences, Shahid Sadoughi University of Medical Sciences, Yazd, Iran

${ }^{4}$ Ph.D. of Biostatistics, Professor, Department of Biostatistics and Epidemiology, School of Public Health, Shahid Sadoughi University of Medical sciences, Yazd, Iran

${ }^{5}$ Ph.D. of Nursing Education, Associate Professor, Department of Nursing Education, Research Center for Nursing and Midwifery Care, Shahid Sadoughi University of Medical Sciences, Yazd, Iran

${ }^{6}$ Ph.D. of Health Education, Professor, Department of Health Education and Promotion, Social Determinants of Health Research Center, School of Public Health, Shahid Sadoughi University of Medical Sciences, Yazd, Iran

Type of article: Original

\begin{abstract}
Background: Marital conflicts and divorce are among the most crucial problems of society. Therefore, it is important to maintain family stability at the optimal level in order to prevent divorce and its consequences in the family and community.

Objective: This study was conducted to design and validate the Family Stability Questionnaire (FSQ) in married couples.

Methods: This study was the second stage of a large study. The FSQ was constructed based on a qualitative research in our previous study in 2016. It was developed through interviews by family therapists, psychiatrists, and couples on 10 dimensions (areas) and was based on McMaster's Family Assessment Device (FAD). Then, in the present study, a confirmatory factor analysis was conducted on 270 males and females (135 couples) of Yazd City (Iran) from January to May 2017. The construct validity and reliability of the scales were examined using exploratory and confirmatory factor analyses (EFA and CFA) and Cronbach's alpha coefficient, respectively. Test-retest reliability was assessed with intra-class correlation coefficients (ICC) for the agreement between the individual items and domains. SPSS 21 and AMOS 21 were used for statistical analyses $(\mathrm{p} \leq 0.05)$.

Results: At first, the results of the CFA on 70 items of FSQ could not confirm (RMSEA=0.06, CFI $=0.91$, $\mathrm{GFI}=0.72$ ), but FSQ with 56 questions indicated that it had sufficiently high validity and reliability to measure family stability (RMSEA $=0.04, \mathrm{CFI}=0.95, \mathrm{GFI}=0.96$ ) with an acceptable fit index. A positive significant correlation was observed between the FSQ and FAD $(r=0.45, p<0.001)$ indicating that FSQ has convergent validity. The Cronbach's alpha and ICC of more than 0.7 in 10 domains of this tool indicated a good internal consistency among the items and their high relevance ( 0.90 and 0.84 , respectively).

Conclusion: FSQ, as a multi-dimensional questionnaire, is a useful and reliable instrument to assess family stability. It consists of ten factors, which were constructed for the first time in Iran. Given the proper features, this instrument can be utilized to carry out more research regarding family stability in Iranian populations.

Keywords: Validation, Family health, Surveys and questionnaires, Factor analysis
\end{abstract}

\section{Corresponding author:}

Professor Dr. Seyed Saied Mazloomy Mahmoodabad, Department of Health Education and Promotion, Social Determinants of Health Research Center, School of Public Health, Safaeeye St, Yazd, Iran.

Tel: +98.3538209108, Email: mazloomy.stu@gmail.com

Received: April 16, 2018, Accepted: July 23, 2018, Published: August 2018

iThenticate screening: July 21, 2018, English editing: August 12, 2018, Quality control: August 14, 2018

This article has been reviewed / commented by four experts

Ethics approval: Shahid Sadoughi University of Medical Sciences (Ref: IR.SSU.SPH.REC.1395.52, July 19, 2016)

(C) 2018 The Authors. This is an open access article under the terms of the Creative Commons Attribution-NonCommercialNoDerivs License, which permits use and distribution in any medium, provided the original work is properly cited, the use is non-commercial and no modifications or adaptations are made. 


\section{Introduction}

Families are among the most significant factors affecting the community. They play an indispensable role in the care of society (1). A healthy family is characterized by functions and characteristics such as appropriate role play, honest interactions and relations, reciprocal respect and perception, enjoying mental and physical health, religious beliefs and values, child-rearing, sincerity, cooperation and coordination, the ability to manage and cope with crises and stresses, happiness, and pleasant activities (2). Based on the McMaster model, the efficient function of the family is a shared struggle for creating and maintaining balance in the family and consists of various categories including problem solving, communication, roles, affective responsiveness, affective involvement, behavioral control and general function (3).

Recently, through the gradual transition from the traditional into the industrial family, the roles of men and women have undergone significant transformation and women are undertaking new roles (4). The social and ethical values governing the relationships among spouses, fathers, mothers, and children have sustained total transformation. Hence, considering the various changes in the family unit, it is expected that there would be some tensions, quarrels, and damage among the members of families (4). The results of studies in other countries indicated that family instability would lead to a wide spectrum of negative consequences including divorce, change in family structure, and behavioral problems in children such as depression, social withdrawal, deficiency in social sufficiency, educational and health problems, and psychosomatic disorders (5-7). On the other hand, family instability induces social instability, changes in social relations, and psychosocial incompatibility, and changes in the economic status and poverty $(8,9)$. Nowadays, divorce constitutes the most important threat against the family foundation. Karney and Bradbury stated in this regard that divorce statistics are among the most valid indices of marital disturbance (10). Marital disputes, conflicts, and divorce are also among the major problems of the Iranian community, so much that according to a 2012 report by the National Organization for Iranian Civil Registration, the number of divorces was 1 in every 6.5 marriages, while this rate increased to 1 in every 5.2 marriages the following year (2015). This trend of rising divorce rate has become a concern for many researchers in the field (11). The statistical information on divorce in Iran indicates an increase in the rate of this problem. The increasing trend of divorce rates around the world and in Iran in recent decades highlights the importance of attempts made to stabilize the family foundations and make it healthy $(12,13)$. Given the significance of the family stabilization policy in Iran, and also the absence of any accurate measurement tool for assessing family stability, carrying out a research aimed at this goal was necessary. Therefore, this study was conducted to construct the scale and validate it in Yazdi couples. Lack of such instruments has led to poor knowledge about familial and social aspects of family stability in an eastern country such as Iran.

Various models have been used to explain family function. Minuchin described six aspects in the structural model of family functioning including: family structure, flexibility, resources, life environment, developmental stages, and the relationship between people's symptoms and family interactive patterns. In Olson's model, two aspects of family behavior including adaptability and facilitators are measured. Some aspects of this model have been criticized. Also, the Beavers model has two aspects: the quality of family interaction, and the level of family adaptability. McMaster's model is a clinical-oriented system model that defines behavioral patterns and important exchange patterns among family members. It is more sensitive in identifying the performance of families, and the correlation between clinical ranking scales and self-scoring scales were higher than other models in a clinical sample (14). This model is founded on a system theory and elucidates all dimensions of the family unit including organization, structure, and marital relationships. It has come together in different aspects of married life, which refer to different approaches and has offered a comprehensive model in this area that can be useful in investigating family life in different groups. Its questionnaire is the Family Assessment Device (FAD) (15). The FAD is the most commonly used scale designed to measure different dimensions of family function. However, it cannot be used for assessing family stability in Iran. Therefore, this first present study was conducted to design and validate and investigate the factor structure of the Family Stability Questionnaire (FSQ) as a comprehensive instrument to entail family stabilization in married couples of Iran.

\section{Material and Methods}

\subsection{Research design, sampling and data collection}

This study was the second stage of a large study. In the first stage, we conducted purposive sampling method through McMaster-based semi-structured interviews to collect data. In this regard, 17 participants were selected based on the inclusion criteria $(16,17)$. Later, the questions of the FSQ were made based on the codes of our qualitative research. In addition, the content validity ratio (CVR), content validity index (CVI), and reliability of the 
FSQ were determined. Then, in a cross-sectional study from January to May 2017, 294 males and females of Yazd City (Iran) who were chosen via cluster random sampling completed the FSQ. Considering a confidence level of 0.95 and the findings of Hajian Moghadam's study (18) (familial factors priority 0.55 and measurement error of 0.065), 226 samples were required. Hence, a total of 294 samples including ten maximally 30 -family clusters were selected using cluster sampling method with cluster sampling index of 1.3. In so doing, 10 urban healthcare centers were selected randomly in Yazd. Each of these centers was considered as a cluster. Then, the researchers tuned to the houses located in the alleys around the center, and 30 subjects ( 15 couples) were selected in each cluster using systematic cluster sampling adding up to a total of 294 subjects. However, 12 couples did not return the questionnaires. Therefore, a total of 270 subjects participated in this study ( 135 couples). The inclusion criteria were as follows: ability to complete the questionnaire, having complete consciousness (including the absence of a history of intellectual disability or psychosis and dementia and having awareness of time, place and person) and lack of a history of major psychiatric disorders such as major depression.

\subsection{Theoretical base}

The theoretical foundations and findings of guided qualitative studies based on McMaster's model were used by the authors of the present paper as a basis for constructing and developing the items in the FSQ. Epstein, Bishop, and Levin introduced the McMaster model to evaluate family functioning at the beginning of $1960 \mathrm{~s}$ at McMaster University. They put forward a comprehensive approach in the domain of family therapy. FAD is the checklist pertaining to this model with 60 items, and evaluates seven domains including communication, problem solving, emotional responses, roles, emotional involvement, general function, and behavioral control (19). Some studies have been done by using this model on families whose function and stability were impaired. For instance, in families with various cultures (20), families with a polygamy basis (21), families with a mentally deficient member (22-24), and families with a physically disabled member $(15,25)$.

\subsection{Family Stability Questionnaire (FSQ)}

In this study, the FSQ was constructed to assess and measure family stability. At first, results of the CFA on 70 items of FSQ could not confirm (RMSEA $=0.06$, Chi-square/df $=2.06, \mathrm{CFI}=0.91$, GFI=0.72) but FSQ with 56 questions, indicated that it has sufficiently high validity and reliability to measure family stability (RMSEA $=0.04$, Chi-square/df $=2.17, \mathrm{CFI}=0.95, \mathrm{GFI}=0.96$ ) with an acceptable fit index. The final version of the inventory consisted of 56 items scored using a 4-point Likert scale as the following: completely agree $=1$, agree $=2$, disagree $=3$, and completely disagree $=4$. This questionnaire included ten categories: communication $(9$ items), problem solving $(5$ items), behavioral control (5 items), affective responsiveness (5 items), roles (6 items), affective involvement (6 items), religious beliefs (4 items), general function ( 7 items), media (4 items), and superstitions (5 items). A high score on each component or for the whole questionnaire indicated inappropriate family stability; hence, the items that indicated inappropriate family stability, were scored reversely $(2,5,7,8,12,14,20,24,25,27,28,30-35,37$ $43,45,46,48,59,60-62,64-67)$.

\subsection{Content validity}

The questionnaire was constructed in the following way:

1) A qualitative study of the directed content analysis type was conducted in 2016 because our research was theorybased $(16,17)$. The participants included 17 individuals (nine family therapists, psychiatrists and eight Yazdi couples) who were selected using purposive sampling method. The participants were selected among those who had sufficient experiences and the power to express them. The data were gleaned with deep semi-structured interviews on the basis of McMaster's model (domains of FAD). Since it is one of the effective and suitable models for investigating the performance of families in Iran, which can be used to prevent the familial and marital problems round the country $(14,26,27)$, it was applied in this study.

2) An items pool was obtained on the basis of the results of the qualitative study (135 items).

3) To establish the face and content validity of the tool, it was given to family therapists and psychiatrists (three psychologists, four family psychologists, and two experienced MSc psychologists) and couples because they had a sufficient amount of experiences (17). It was revised and improved on the basis of their opinions. Subsequently, the content validity index (CVI) and the content validity ratio (CVR) of the questionnaire were calculated and the items with CVR and CVI values $<0.70$ were eliminated. To determine content validity ratio (CVR), we used the Lawshe method (28). The family therapists and psychiatrists were further asked to examine the face validity of the tool through assessing the suitability of the items. They evaluated the necessity of the items using a 3-point rating scale: 1) not necessary; 2) useful, but not essential; 3) essential. Subsequently, experts judged the clarity, simplicity, and 
relevancy of each item on a 4-point scale from not relevant, not simple, and not clear (1) to very relevant, very simple, and very clear (4). In this stage, 70 items were approved.

4) The items in each category and the scoring method were determined.

5) Structural equation modeling (SEM) of the questionnaire was determined.

6) The final version of the questionnaire including 56 items along with its psychometric features (validity, SEM and reliability) was constructed, which is presented under the results section. It is mentioned that the original version of the scale consisted of 70 items and after calculating CVI, CVR and CFA, 14 questions were omitted.

\subsection{Equivalence and Stability reliability}

Cronbach's alpha was applied to estimate the internal consistency reliability. Test-retest reliability was evaluated using intra-class correlation coefficients for agreement between the individual items and domains with a 2 -week interval. Cronbach's alpha values of 0.70 or greater is considered to indicate satisfactory internal consistency (29).

\subsection{Construct validity}

To determine the validity of the instrument, content validity, factor analysis, and convergent validity (correlation between FSQ and FAD) were used. To investigate the construct validity, the questionnaire performance was assessed using CFA. The missing values were substituted with the mean. The study sample consisted of 135 couples (270 males and females) who completed the questionnaire.

\subsection{Ethical consideration}

The Committee of Ethics in Human Research from the School of Health (Shahid Sadoughi University of Medical Sciences, Yazd, Iran) approved the ethics of the study (Ref: IR.SSU.SPH.REC.1395.52). The participants of the study were assured of information confidentiality and anonymity, and voluntary participation in the study. Informed written consent was obtained from participants after the study purposes and goals were explained to them.

\subsection{Statistical analysis}

Data analysis was performed by IBM(C SPSSC Statistics version 21 (IBMC Corp., Armonk, NY, USA) and AMOS version 21. Cronbach's alpha coefficient and intra-class correlation coefficients (ICC) were used to investigate the reliability of the FSQ. Also, CFA was conducted to investigate the factorial structure of the questionnaire via structural equation modeling. The fitness and validity of the questionnaire were investigated via CFA using comparative fit index (CFI), relative Chi-square /df, normed fit index (NFI), goodness of fit index (GFI), relative fit index (RFI), and root mean square error of approximation (RMSEA). A p-value of $\leq 0.05$ was set as the significant level.

\section{Results}

\subsection{Socio-demographic characteristics}

In the qualitative stage in 2016, a total of about 1,430 initial codes without consideration of overlap and 557 initial codes with consideration of overlap were extracted. These codes were placed in 69 subcategories, 28 categories and 10 themes (domains) based on the differences and similarities. Themes of the McMaster model (seven domains) as well as three domains of religious beliefs, superstitions, and media were conceptualized and abstracted. Later, the questions of FSQ were made based on the codes. The mean age of the 135 males and females was $42.3(\mathrm{SD}=12.5)$ and $37.7(\mathrm{SD}=11.5)$ years, respectively. Most had a diploma or under diploma $(61.5 \%$ of men, $\mathrm{n}=166$ and $70.3 \%$ of women, $\mathrm{n}=190)$. Duration of marriage in 136 persons $(50.4 \%)$ was between 11-30 years, duration of acquaintance before marriage in 146 persons $(53.7 \%)$ was less than 6 months and age difference of 158 males and females $(58.5 \%)$ was between $0-5$ years.

\subsection{Reliability}

The inventory showed a high internal consistency (Cronbach's alpha $=0.90)$. The intra-class correlation coefficients obtained (ICC) was 0.84 (95\% CI: 0.85-0.94, p<0.001) suggesting proper stability of the questionnaire (Table 1).

\subsection{Exploratory Analysis}

The Kaiser-Meyer-Olkin (KMO) test was performed to confirm the sample adequacy (Table 2). Also, for assessing the priorities of the FSQ components, the principal component analysis method was used. The values above 0.7 for the KMO test and the statistical significance of the Bartlett's test indicate sampling adequacy for factor analysis (30). All factors related to family stability were entered into the factor analysis. Then, rotation of Varimax was used to extract the possible factors in the questionnaire. In our study, the value of KMO and Bartlett's sphericity tests for 
specific family stability were 0.85 and 9169.611 , respectively $(\mathrm{p}<0.001)$ that was significant and confirmed the feasibility of confirmatory factor analysis. The KMO value indicated that factor analysis was appropriate for the data (Table 2). Finally, 10 factors (which were the indicators for family stability in couples of Yazd) remained in the instrument based on the output command. The results of total variance explained revealed 10 factors with a value higher than one. The Eigen values of the factors were 8.30, 5.19, 4.42, 3.92, 3.10, 3.09, 2.46, 2.46, 2.43, and 2.20 respectively. Also, the variance percentages of the test were 15.86, 9.41, 7.32, 6.60, 4.42, 4.41, 3.52, 3.52, 3.48, and 3.15 respectively. Overall, $61.69 \%$ of total variance explains the test variables.

Table 1. Cronbach's alpha coefficients and ICC of the FSQ

\begin{tabular}{|l|l|l|}
\hline Subscales & Cronbach's alpha & ICC \\
\hline General function & 0.824 & 0.826 \\
\hline Problem solving & 0.702 & 0.697 \\
\hline Communication & 0.915 & 0.907 \\
\hline Affective involvement & 0.863 & 0.860 \\
\hline Affective responsiveness & 0.817 & 0.809 \\
\hline Roles & 0.861 & 0.858 \\
\hline Behavior control & 0.772 & 0.767 \\
\hline Religious beliefs & 0.918 & 0.912 \\
\hline Media & 0.794 & 0.792 \\
\hline Superstitions & 0.903 & 0.901 \\
\hline Total & 0.901 & 0.842 \\
\hline
\end{tabular}

ICC: intra-class correlation coefficients

Table 2. Kaiser-Meyer-Olkin and Bartlett's Test

\begin{tabular}{|l|l|l|l|}
\hline Kaiser-Meyer-Olkin Measure of Sampling Adequacy & Bartlett's Test of Sphericity & df & Sig. \\
\hline 0.849 & 9169.611 & 2415 & 0.000 \\
\hline
\end{tabular}

\subsection{Confirmatory Content Analysis}

In the present study, seeing that the SEM of the FSQ was predetermined on the basis of theoretical foundations, CFA was used to establish the construct validity of the questionnaire. The results are displayed in Table 3. The results demonstrated that the 10 -factor structure of the FSQ with 70 items enjoys good fitness of the model since these indices have acquired the required standards. Nonetheless, an investigation of the factor loadings of the questionnaire items suggested that the factor loadings of items $3,11,13,14,51,54$ and 63 were not statistically significant. Moreover, some items of the questionnaire had negative factor loadings. Hence, these items were examined by the research team to be properly revised and maintained or deleted. Ultimately, on the basis of theoretical findings and the obtained results, of 70 items, only 14 items including items $3,11,13,16,17,19,29,44$, $51,52,54,63,68$ and 69 were omitted and only 56 items remained. It should be pointed out that some items were kept in the questionnaire due to their theoretical importance despite lack of statistical significance. After omission of these 14 items, CFA was run again for the 10-factor structure of the FSQ with 56 items. The results of this analysis given in Table 3 revealed that the overall indices of model fit have improved with respect to the required criteria for each. Thus, it could be said that the 10-factor structure of FSQ enjoys acceptable fit. Figure 1 revealed the final output of AMOS software. Standard regression weights of FSQ domains are revealed in Table 4. The $p$ values in all domains were less than 0.05 . Table 5 displays the results of CFA factor loadings of the 56 -item version of the FSQ and standard regression weights of the questions. The factor loadings matrix given in Table 5 indicates that except for the factor loading of item 14 ( $\mathrm{t}=0.09, \mathrm{p}>0.05)$, other factor loadings are statistically significant. Therefore, item distribution in the FSQ subscales is compatible with the 10-factor structure presented for this instrument. It should be noted that although the factor load of item 14 was not significant, this item was not omitted from the questionnaire because of the importance of its theoretical foundations. Subsequently, statistical analyses were performed in the presence of this item. Generally speaking, it can be asserted that the 10-factor FSQ with 56 items can be approved, indicating the appropriate construct validity of this tool. In this research, McMaster's Family Assessment Device was used to determine the convergent validity of FSQ. To do so, the correlation between FSQ scores and FAD scores was estimated. Pearson's correlation coefficients indicated a positive significant correlation between the two $(\mathrm{r}=0.45, \mathrm{p}<0.001)$. Thus, the results indicated the good convergent validity of FSQ. The correlation between domains of general function $(\mathrm{r}=0.70)$, problem solving $(\mathrm{r}=0.45)$, communication $(\mathrm{r}=0.58)$, affective 
involvement $(\mathrm{r}=0.64)$, affective responsiveness $(\mathrm{r}=0.51)$, roles $(\mathrm{r}=0.63)$ and behavioral control $(\mathrm{r}=0.60)$ in $\mathrm{FAD}$ and FSQ was positive and appropriate.

Table 3. Confirmatory factor analysis indices of Family Stability Questionnaire

\begin{tabular}{|l|l|l|l|l|l|l|l|l|}
\hline Model & $\chi^{2} / \mathrm{df}$ & $\chi^{2}$ & $\mathrm{df}$ & CFI & GFI & RFI & NFI & REMSEA \\
\hline Before omitting the questions & 2.06 & 4758.22 & 2300 & 0.91 & 0.72 & 0.84 & 0.85 & 0.06 \\
\hline After omitting the questions & 2.17 & 3193.901 & 1439 & 0.95 & 0.97 & 0.96 & 0.96 & 0.04 \\
\hline
\end{tabular}

CFI: comparative fit index; GFI: goodness of fit index; RFI: relative fit index; NFI: normed fit index; REMSEA: root mean square error of approximation

Table 4. Standard regression weights of FSQ ( $\mathrm{xx}$ ) domains

\begin{tabular}{|l|l|l|l|l|l|}
\hline Family stability & \multicolumn{2}{|l|}{ Domains } & Estimate & S.E. & C.R. \\
\hline $\mathrm{xx}$ & $\rightarrow$ & $\mathrm{x} 1$ & 0.461 & 0.052 & 8.937 \\
\hline $\mathrm{xx}$ & $\rightarrow$ & $\mathrm{x} 2$ & 0.346 & 0.042 & 8.197 \\
\hline $\mathrm{xx}$ & $\rightarrow$ & $\mathrm{x} 3$ & 0.303 & 0.050 & 6.017 \\
\hline $\mathrm{xx}$ & $\rightarrow$ & $\mathrm{x} 4$ & 0.634 & 0.048 & 13.164 \\
\hline $\mathrm{xx}$ & $\rightarrow$ & $\mathrm{x} 5$ & 0.633 & 0.047 & 13.389 \\
\hline $\mathrm{xx}$ & $\rightarrow$ & $\mathrm{x} 6$ & 0.525 & 0.046 & 11.320 \\
\hline $\mathrm{xx}$ & $\rightarrow$ & $\mathrm{x} 7$ & 0.230 & 0.039 & 5.14190 \\
\hline $\mathrm{xx}$ & $\rightarrow$ & $\mathrm{x} 8$ & 0.240 & 0.041 & 5.845 \\
\hline $\mathrm{xx}$ & $\rightarrow$ & $\mathrm{x} 9$ & 0.341 & 0.050 & 6.806 \\
\hline $\mathrm{xx}$ & $\rightarrow$ & $\mathrm{x} 10$ & 0.400 & 0.048 & 8.270 \\
\hline
\end{tabular}

S.E.: Standard Error, C.R.: Critical Ratio

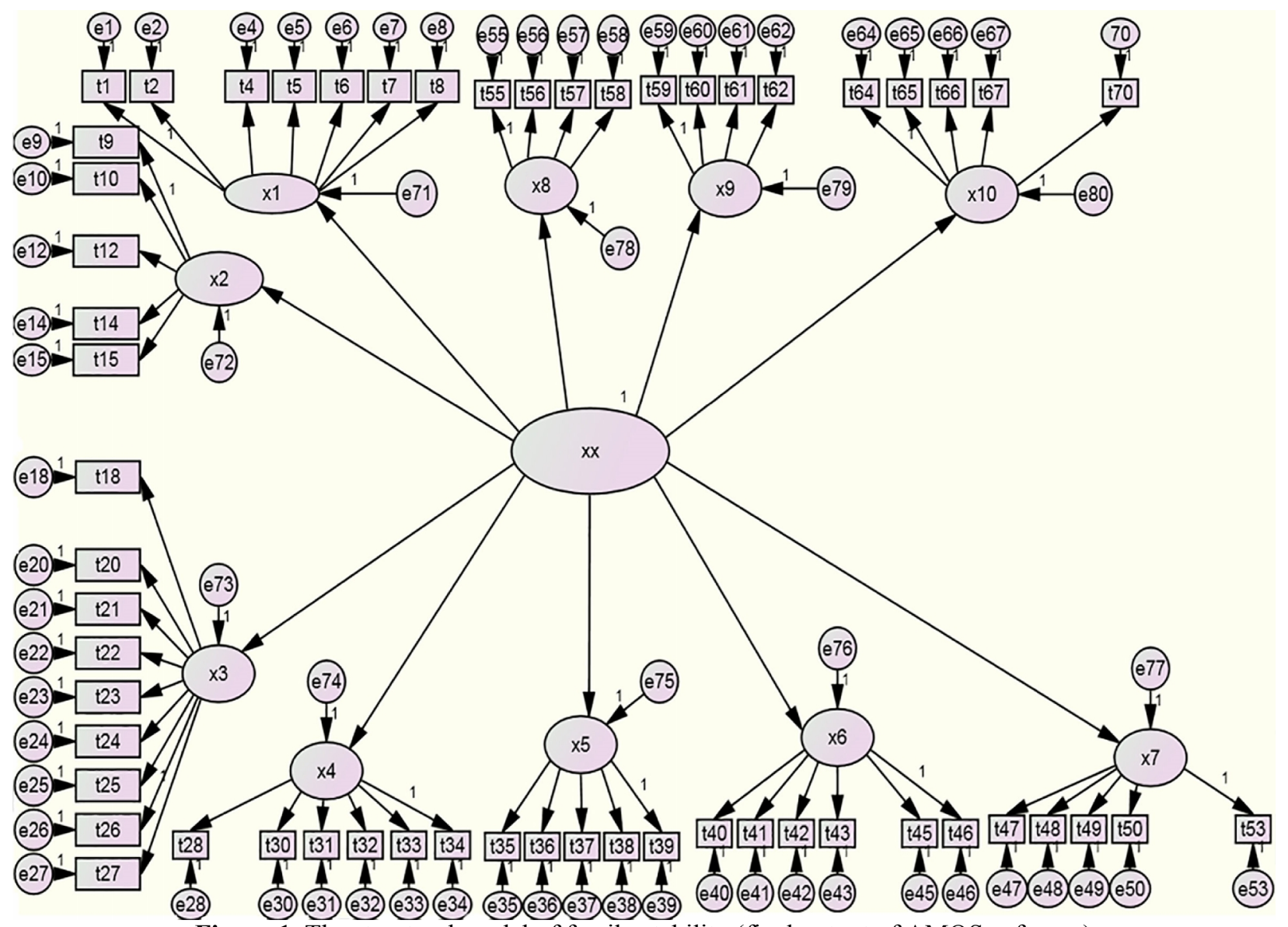

Figure 1. The structural model of family stability (final output of AMOS software) 
Table 5. Factor loadings and standard regression weights of FSQ items and their significance in terms of subscales

\begin{tabular}{|c|c|c|c|}
\hline Subscale & Questions & $\begin{array}{l}\text { Factor } \\
\text { loadings }\end{array}$ & $\begin{array}{l}\text { S.R } \\
\text { weights }\end{array}$ \\
\hline \multirow{7}{*}{$\begin{array}{l}\text { General } \\
\text { function }\end{array}$} & Our family members are open and honest to each other. & 0.25 & 0.698 \\
\hline & Our family members do not understand each other. & 0.57 & 1.000 \\
\hline & $\begin{array}{l}\text { In our family, some members forgo their own wishes in order to advance other family } \\
\text { members. }\end{array}$ & 0.36 & 0.523 \\
\hline & In our family, opinions of the children are seldom taken into account. & 0.65 & 1.196 \\
\hline & If a family member becomes physically ill, others will help him or her. & 0.44 & 0.668 \\
\hline & If a family member suffers from a mental illness, others will pay no attention to it. & 0.68 & 1.258 \\
\hline & Our family members are not tolerant of each other's problems & 0.60 & 1.096 \\
\hline \multirow{5}{*}{$\begin{array}{l}\text { Problem } \\
\text { solving }\end{array}$} & We usually use all possible means to solve family problems. & 0.55 & 1.000 \\
\hline & $\begin{array}{l}\text { If we do not find a solution to the problems of the family, we accept the reality and } \\
\text { move on. }\end{array}$ & 0.29 & 0.508 \\
\hline & $\begin{array}{l}\text { In solving family problems, usually some members try to force their own views on } \\
\text { other family members. }\end{array}$ & 0.45 & 1.076 \\
\hline & In solving our family problems, the father usually makes the final decision. & 0.09 & 0.342 \\
\hline & When making family decisions, our family members are respectful of each other. & 0.63 & 1.217 \\
\hline \multirow[t]{9}{*}{ Communication } & Our family sincerely discuss their true feelings. & 0.31 & 0.706 \\
\hline & If we do not like the behavior of a family member, we ignore him or her. & 0.51 & 1.529 \\
\hline & We talk to each other to resolve disagreements and misunderstandings. & 0.54 & 1.280 \\
\hline & We try hard to find out why another family member is upset. & 0.55 & 1.273 \\
\hline & Our family members do not keep any secrets from each other. & 0.42 & 1.136 \\
\hline & Occasionally, there is a physical fight in our family. & 0.61 & 1.836 \\
\hline & When there is a disagreement in our family, we can expect verbal abuse. & 0.59 & 1.839 \\
\hline & In our family, children respect each other and their parents. & 0.54 & 1.331 \\
\hline & Our family members expect a lot from each other. & 0.36 & 1.000 \\
\hline \multirow[t]{6}{*}{$\begin{array}{l}\text { Affective } \\
\text { involvement }\end{array}$} & $\begin{array}{l}\text { Our family is very busy, physically and mentally; hence expectations of other family } \\
\text { members are not taken into account. }\end{array}$ & 0.61 & 0.757 \\
\hline & In our family, we cooperate with each other only when it is in our own best interest. & 0.56 & 0.700 \\
\hline & In our family, children and their mother always unite against the father. & 0.70 & 0.953 \\
\hline & We rarely set aside time for other family members. & 0.58 & 0.712 \\
\hline & In our family, children are independent and self-centered. & 0.75 & 0.951 \\
\hline & In our family, children do not pay attention to the wishes of parents & 0.79 & 1.000 \\
\hline \multirow{5}{*}{$\begin{array}{l}\text { Affective } \\
\text { responsiveness }\end{array}$} & Our family members are not able to express their affection towards each other. & 0.51 & 0.621 \\
\hline & It is difficult for our family members to be away from the family. & 0.22 & 0.821 \\
\hline & In our family, no attention is paid to children's feelings and emotions. & 0.73 & 0.871 \\
\hline & $\begin{array}{l}\text { After a prolonged physical illness of a family member, we get tired of taking care of } \\
\text { him or her. }\end{array}$ & 0.83 & 0.936 \\
\hline & $\begin{array}{l}\text { After a prolonged mental illness of a family member, we get tired of taking care of him } \\
\text { or her. }\end{array}$ & 0.85 & 1.000 \\
\hline \multirow[t]{6}{*}{ Roles } & Our family members do not perform their duties. & 0.74 & 1.130 \\
\hline & In our family, women assume most of the responsibilities. & 0.61 & 0.888 \\
\hline & When it comes to housework, our family members are not cooperative. & 0.78 & 1.162 \\
\hline & The responsibilities in our family are not properly distributed among members. & 0.69 & 1.007 \\
\hline & $\begin{array}{l}\text { When something needs to be done by a family member, he or she must be reminded } \\
\text { many times. }\end{array}$ & 0.51 & 0.699 \\
\hline & We are not satisfied with the division of responsibilities in our family. & 0.71 & 1.000 \\
\hline \multirow{5}{*}{$\begin{array}{l}\text { Behavior } \\
\text { control }\end{array}$} & There are certain rules in our family that must be followed. & 0.43 & 1.581 \\
\hline & In our family, comings and goings are under control. & 0.74 & 0.994 \\
\hline & $\begin{array}{l}\text { We have rules for using social and mass media such as virtual networks, satellite } \\
\text { services, etc. }\end{array}$ & 0.45 & 3.275 \\
\hline & If one of our family members arrives home late, he or she will be held accountable. & 0.50 & 1.606 \\
\hline & When it comes to dressing, our family has certain rules & 0.25 & 1.000 \\
\hline
\end{tabular}




\begin{tabular}{|l|l|l|l|}
\hline \multirow{3}{*}{$\begin{array}{l}\text { Religious } \\
\text { beliefs }\end{array}$} & $\begin{array}{l}\text { Religious beliefs play an important role in reducing tensions between our family } \\
\text { members. }\end{array}$ & 0.67 & 1.000 \\
\cline { 2 - 3 } & Religious beliefs play a role in maintaining the stability of our family. & 0.75 & 1.085 \\
\cline { 2 - 3 } & Because of our religious beliefs, we do not criticize each other. & 0.64 & 1.128 \\
\cline { 2 - 4 } & $\begin{array}{l}\text { Because of our religious beliefs, when we get upset by another family member, we do } \\
\text { not retaliate. }\end{array}$ & 0.54 & 0.972 \\
\hline \multirow{5}{*}{ Media } & $\begin{array}{l}\text { In our family, the presence of satellite services and social media (Telegram, } \\
\text { WhatsApp, etc.) has caused suspicion and mistrust among family members. }\end{array}$ & 0.72 & 1.000 \\
\cline { 2 - 4 } & $\begin{array}{l}\text { Virtual networks and satellite services have caused bad feelings and divisions within } \\
\text { our family. }\end{array}$ & 0.86 & 1.200 \\
\cline { 2 - 4 } & $\begin{array}{l}\text { In our family, the presence of satellite services and virtual networks (Telegrams, } \\
\text { WhatsApp, etc.) has led children to oppose their parents }\end{array}$ & 0.82 & 1.015 \\
\cline { 2 - 4 } & $\begin{array}{l}\text { Some radio and television programs have a negative and unintended effect on the } \\
\text { behavior of our family members. }\end{array}$ & 0.30 & 0.354 \\
\hline & $\begin{array}{l}\text { Our family members are sometimes willing to pay a psychic or a witch doctor instead } \\
\text { of seeking a specialist's advice. }\end{array}$ & 0.77 & 1.000 \\
\cline { 2 - 4 } & We sometimes go to a psychic or a witch doctor to solve our problems. & 0.90 & 1.165 \\
\cline { 2 - 4 } & $\begin{array}{l}\text { Our family members believe that some psychics can induce affection or cause } \\
\text { disagreement and separation. }\end{array}$ & 0.80 & 1.028 \\
\cline { 2 - 4 } & In our family, it is considered inappropriate for women to work outside the house. & 0.39 & 0.569 \\
\cline { 2 - 4 } & We do not resort to superstition to escape the adversities of life. & 3.257 \\
\hline
\end{tabular}

\section{Discussion}

The FSQ was developed to fulfill the need for a culturally tailored instrument measuring family stability in married Yazdi couples (Iran). This study was the first to design and test the scale's reliability and construct validity. It is a self-reported measure of family stability, with good internal consistency and convergent validity. It can help in identifying families who have some problems among their members with regard to their relationships and functions. Also, in this questionnaire, an attempt has been made to create a balance between the mental and physical needs of the families. The strong point of the study can be attributed to the thorough research methodologies that were employed. We conducted a qualitative study with purposive sampling method through semi-structured interviews to collect data (in our previous study). Then, the FSQ items pool embraced the full spectrum of family stability in the couples. Our large sample size was adequate for the validation, and random geographic-clustered subject sampling was effective in yielding a participant population representative of Yazd, Iran.

The results of CFA revealed that the overall indices of model fit have improved with respect to the required criteria for each variable. Thus, it could be said that the 10-factor structure of FSQ enjoys acceptable fit. The scale is a highly useful multi-dimensional instrument with high reliability. It can serve as a suitable scale for measuring family stability and indicates individuals' perceptions of their families with greater detail because it entails 10 categories (factors) with high internal relations and consistency. The ten factors included problem solving, communication, roles, affective responsiveness, affective involvement, behavior control, religious beliefs, media, and superstitions. Epstein proposed a seven-factor model for family function including concerns about general function, problem solving, communication, roles, affective responsiveness, affective involvement, and behavior control (31). Moreover, the Cronbach's alpha coefficients were estimated for the ten domains separately. High values for Cronbach's alpha revealed good internal consistency of the items in the ten domains. Higher Cronbach's alpha demonstrated a high correlation among the items, indicating that the questionnaire is consistently reliable (32). Cronbach's alpha correlation coefficient indicated high and satisfactory reliability of the factors, so that all the extracted factor loadings were statistically significant and the distribution of items in the subscales (categories) of this questionnaire was compatible with the 10 -factor structure used in this study. Alpha coefficient was higher than 0.90 for the subscales of communication, religious beliefs, and superstitions and it was higher than 0.80 for the subscales of general function, affective involvement, affective responsiveness, and roles. These findings are consistent with the results of the studies by Epstein (27,31), Zadeh Mohammadi (14), and Boterhoven de Haan (33) that all indicated the homogeneity of the FSQ and FAD for measuring people's perceptions of their families. In Zadeh Mohammadi's study, high correlations between the scores of the domains and total score were observed (14). Also, the results of Boterhoven de Haan's study demonstrated that "the subscales of the short version of the general functioning of the McMaster FAD had virtually equivalent psychometric properties and were able to identify almost 
all of the same families who had healthy or unhealthy levels of functioning as the full subscale. The findings support the use of the short version of FAD, as a quick and effective tool to assess the overall functioning of families" (33). Our findings also indicated a positive significant correlation between the FSQ domains and FAD. The correlation is consistent with the results of the studies by Beavers (34) and Kabacoff (35). FAD was examined in different populations and there are similar domains, but in attention to different cultures of Iranian people, constructing and validating of a questionnaire for assessing family stability was necessary. Because FSQ was the first instrument for measuring family stability, it was not possible to find its harmony with previous research. There is no obvious evidence in the literature; therefore, we had to compare it with studies on McMaster's model as our base pattern in order to investigate possible sources of the different results of the present study.

On the whole, it may be postulated that the questionnaire developed by McMaster's criteria is consistent in the categories "problem solving, communication, roles, affective responsiveness, affective involvement, and behavior control" (36). Additionally, it is consistent with Minuchin's study in problem solving power (37), with Olson's study (38) and Samani's study in models of good communication and verbal and non-verbal interactions, duties and roles, responsibility, expression of feelings, and religious beliefs (39), and with Hair's study in psychosomatic health and the quality of adolescent-parent relations (40). Indeed, many of the studies above have dealt with one or more family stability components. The FSQ has three new domains in addition to the FAD's subscales that include religious beliefs, superstitions, and media (41). Generally speaking, it can be asserted that the 10-factor FSQ with 56 items was approved indicating that the appropriate construct validity of this tool and the fit indices are acceptable. The scales were not examined in different populations and it is necessary to conduct more validation studies on the scales. Regarding convergent validity, it was expected that the correlation coefficient between the scores of the FSQ and FAD be strong $(r>0.7)$ whereas it was under moderate $(r=0.45)$, indicating that the FSQ measures different aspects of family function and stability. Experts' opinions were used to determine the content validity. They discussed the wording and relevance of the scales' items for Yazdi people's culture. No item had a CVR $<0.7$, indicating a satisfactory content validity. Subsequently, experts judged the clarity, simplicity, and relevancy of each item. No item had a CVI less than 0.7 , recommended as acceptable CVI by nine experts.

\section{Strength and limitation of study}

The instrument developed in this study can be beneficial in screening family stability among couples, and family therapy in consulting settings, especially for resolving familial problems. It is also useful and applicable in research centers. The use of groups of experts such as specialists, statisticians, and methodologists in the study was a strong point. Also, the data for construction of FSQ were gleaned with deep semi-structured interviews on the basis a qualitative study. Because the scale was examined on the population of Yazd city and since it is a new scale for measuring family stability, it is recommended that future studies be conducted by other scholars in other cities to validate this tool in those settings. Finally, it can be used in consultation centers and family stability clinics to deal with problematic families. The present study had some limitations. It was conducted in just one city in Iran; therefore, further validation studies should be performed in other populations representing greater geographic, financial and ethnic diversity and in a larger sample of couples. One other limitation of the study was that the FSQ relies on self-report and thus does not detect implicit processes. Also, because it was carried out on people who were willing to cooperate (which is ethically logical), we must be wary of generalizations. Lack of full control on confounding variables such as the personality of individuals, socioeconomic and cultural variables was another limitation of this research.

\section{Conclusions}

FSQ as a multi-dimensional questionnaire is a useful and reliable instrument to assess family stability among Yazdi couples. It consists of ten factors, and was constructed for the first time in Iran. Further research should be designed to examine the validity of the FSQ in other Iranian couples. Given the proper features, this instrument can be utilized to carry out more research regarding family stability in Iranian populations.

\section{Acknowledgments:}

This article was extracted from a PhD dissertation concerned with Social Determinants of Health Research Center (Ref: p/17/1/30855, May 10, 2016). The researcher would like to thank the Committee of Ethics in Human Research at the School of Public Health (Shahid Sadoughi University of Medical Sciences), which approved and financed this work. We should also thank all the experts, psychiatrists, psychologists and couples who supported us patiently for collecting the data. 


\section{Conflict of Interest:}

There is no conflict of interest to be declared.

\section{Authors' contributions:}

All authors contributed to this project and article equally. All authors read and approved the final manuscript.

\section{References:}

1) Callan S. Building a strong society requires effective family policy, DIFI Family Research and Proceedings. 2014: 1. doi: 10.5339/difi.2014.1.

2) Sadeghi M, Fatehizadeh M, Ahmadi A, Bahrami F, Etemadi O. Developing a model of healthy family based on an Explorative Mixed Method Research. Family. Psychology. 2014; 1(1): 29-40.

3) Barney MC, Max JE. The McMaster family assessment device and clinical rating scale: Questionnaire vs interview in childhood traumatic brain injury. Brain Inj. 2005; 19(10): 801-9. doi: 10.1080/02699050400024961. PMID: 16175840.

4) Mahmoudian $\mathrm{H}$, Khodamoradi $\mathrm{H}$. Investigating the relationship of socio economic progress and divorce rate among cities in 2006. Social Security Studies. 2006; (23): 13-41.

5) Cavanagh S, Huston A. Family instability and children's early problem behavior. Social Forces. 2006; 85(1): 551-81. doi: 10.1353/sof.2006.0120.

6) Waldfogel J, Craigie TL, Brooks-Gunn J. Fragile Families and Child Wellbeing. Future Child. 2010; 20(2): 87-112. PMID: 20964133, PMCID: PMC3074431.

7) Craigie TL, Brooks-Gunn J,Waldfogel J. Family Structure, Family Stability, and Outcomes of Five-YearOld Children. Fam Relatsh Soc. 2012; 1(1): 43-61. doi: 10.1332/204674312X633153.

8) Goldberg JS, Carlson MJ. Parents' Relationship Quality and Children's Behavior in Stable Married and Cohabiting Families. J Marriage Fam. 2014; 76(4): 762-77. doi: 10.1111/jomf.12120.

9) Brown Susan L. Marriage and Child Well-being: Research and Policy Perspectives. J Marriage Fam. 2010; 72: 1059-77.doi: 10.1111/j.1741-3737.2010.00750.x.

10) Karney BR, Bardbury TN. Neuroticism, marital interaction and trajectory of marital satisfaction. J Pers Soc Psychol. 1997: 1075-92. PMID: 9150586.

11) Ghoroghi S, Aishah Hassan S, Baba M. Marital Adjustment and Duration of Marriage among Postgraduate Iranian Students in Malaysia. International Education Studies. 2015; 8(2): 50-9. doi: 10.5539/ies.v8n2p50.

12) Zarei F, Solhi M, Merghati-khoei E, Taghdisi MH, Shojaeizadeh D, Taket AR, et al. Development and Psychometric Properties of Social Exclusion Questionnaire for Iranian Divorced Women. Iran J Public Health. 2017; 46(5): 640-9. PMID: 28560195, PMCID: PMC5442277.

13) Lester D. Trends in Divorce and Marriage around the World. Journal of Divorce \& Remarriage. 1996; 25(1-2): 169-71. doi: 10.1300/J087v25n01_11.

14) Zadeh Mohammadi A, Malek Khosravi GH. A preliminary study of validity and psychometric characteristics of family functioning Assessment (FAD). Quarterly of Family Research. 2006; 5(2): 69-89.

15) Zanganeh B, Kaboudi M, Ashtarian H, Kaboudi B. The comparison of family function based on the McMaster model in fertile and infertile women. Journal of Medicine and Life. 2015; 8(4): 196-202. PMID: 28316731, PMCID: PMC5319294.

16) Hsieh HF, Shannon SE. Three approaches to qualitative content analysis. Qual Health Res. 2005; 15: 1277 88. doi: $10.1177 / 1049732305276687$.

17) Pourmovahed Z, Mazloomy Mahmoodabad SS, Zareei Mahmoodabadi H, Tavangar H, Yassini Ardekani SM, Vaezi AA. Deficiency of self-efficacy in problem-solving as a contributory factor in family instability: a qualitative study. Iranian Journal of Psychiatry. 2018; 13: 32-9. PMCID: PMC5994226

18) Hajian moghadam F. A Meta-Analysis in Family Studies: Strengthening and Distorting Factors in Iranian's Families. Women's Studies. 2014; 5(1): 1-39.

19) Gholizadeh H, Bayrami M, Farnam A, Imani M, Pirzade J. A comparison of Family functioning in obsessive compulsive disorder patients with healthy subjects. Urima Med J. 2010; 21(4): 354-60.

20) Kim YP, Joh JY, Shin IS. Family function of the families consisting of Asian immigrant women living in South Korea: A 3-Year longitudinal study. Asia-Pacific Journal of Public Health. 2015; 27(2): NP2702-11. doi: 10.1177/1010539512446958.

21) Al-Krenawi A. A study of psychological symptoms, family function, marital and life satisfactions of polygamous and monogamous women: The Palestinian case. International Journal of Social Psychiatry. 2012; 58(1): 79-86. doi: 10.1177/0020764010387063. 
22) Gau SS-F, Chou MC, Chiang HL, Lee JC, Wong CC, Chou WJ, et al. Parental adjustment, marital relationship, and family function in families of children with autism. Research in Autism Spectrum Disorders. 2012; 6(1): 263-70. doi: 10.1016/j.rasd.2011.05.007.

23) Yang S, Hong JA. Factors influencing family function in families of pathological gamblers. Journal of Korean Academy of Psychiatric and Mental Health Nursing. 2015; 24(3): 196-206. doi: 10.12934/jkpmhn.2015.24.3.196.0.

24) Zhang D, Chen L, Yin D, Miao J, Sun Y. Study on the correlation among adolescents' family function, negative life events stress amount and suicide ideation. Wei Sheng Yan Jiu = Journal of Hygiene Research. 2014; 43(4): 581-5. PMID: 25199285.

25) Lax Pericall MT, Taylor E. Family function and its relationship to injury severity and psychiatric outcome in children with acquired brain injury: a systematized review. Developmental Medicine \& Child Neurology. 2014; 56(1): 19-30. doi: 10.1111/dmcn.12237, PMID: 23980643.

26) Zareei Mahmood Abadi H. The Effectiveness of Retraining Attribution Styles (Cognitive Therapy) on Dimensions of Family Functioning in Divorce Applicant Couples. International Journal of Psychological Studies. 2012; 4(2): 257-263. doi: 10.5539/ijps.v4n2p257.

27) Epstein NB, Baldwin LM, Bishop DS. The McMaster Family Assessment Device. Journal of Marital and Family therapy. 1983; 9(2): 171-80. doi: 10.1111/j.1752-0606.1983.tb01497.x.

28) Lawshe C. A quantitative approach to content validity. Pers Psychol. 1975; 28: 563-75. doi: 10.1111/j.1744-6570.1975.tb01393.x.

29) Streiner D. Starting at the Beginning: An Introduction to Coefficient Alpha and Internal Consistency. J Pers Assess. 2003; 80(1): 99-103. doi: 10.1207/S15327752JPA8001-18. PMID: 12584072.

30) GhanbariA, Hasandoost F, Kazemnezhad Lyili E, Tabari Khomeiran R, Momeni M. Assessing Emergency Nurses' Clinical Competency: An Exploratory Factor Analysis Study. Iranian Journal of Nursing and Midwifery Research. 2017; 22(4): 280-6. doi: 10.4103/1735-9066.212990. PMCID: PMC5590357.

31) Epstein NB, Bishop DS, Levine S. The McMaster model of family functioning. Journal of Marriage and Family Counseling. 1978; 4: 19-31. doi: 10.1111/j.1752-0606.1983.tb01497.x.

32) Parsian N, Dunning T. Developing and validating a questionnaire to measurespirituality: a psychometric process. Glob J Health Sci. 2009; 1(1): 2-11. doi: 10.5539/gjhs.v1n1p2.

33) Boterhoven de Haan KL, Hafekost J, Lawrence D, Sawyer MG, Zubrick SR. Reliability and Validity of a Short Version of the General Functioning Subscale of the McMaster Family Assessment Device. Fam Process. 2015; 54(1): 116-23. doi: 10.1111/famp.12113. Epub 2014 Nov 11.

34) Beavers R, Hampson RB. The Beavers system model of family functioning. Journal of Family Therapy. 2000; 22: 128-43. doi: 10.1111/1467-6427.00143.

35) Kabacoff RI, Miller IW, Bishop DS, Epstein NB, Keitner GI. A Psychometric Study of the McMaster Family Assessment Device in Psychiatric, Medical, and Non clinical Samples. Journal of Family Psychology. 1990; 3 (4): 431-9. doi: 10.1037/h0080547.

36) Ryan CE, Epstein NB, Keitner GI, Miller IW, Bishop DS. Evaluating and treating families: The McMaster approach. Prim Care Companion J Clin Psychiatry. 2009; 11(4): 176. doi: 10.4088/PCC.08bk00770.

37) Minuchin S. Where is the family in narrative family therapy? J Marital Fam Ther. 1998; 24(4): 397-403. PMID: 9801999.

38) Olson DH, Russell CS, Sprenkle DH. Circumplex model of marital and family systems: VI. Theoretical update. Fam Process. 1983; 22(1): 69-83. PMID: 6840263.

39) Samani S, Kayyer M, Sedaghat Z. Parenting Style in Different Types of Family in the Family Process and Content Model. Journal of Family Research. 2010; 6(2): 161-74.

40) Hair EC, Moore KA, Hadley AM, Kaye K, Day RD, Orthner DK. Parent marital quality and the parentadolescent relationship: Profiles of relationship quality. Marriage \& Family Review. 2009; 45(2-3): 189217. doi: 10.1080/01494920902733500.

41) Pourmovahed Z, Mazloomy Mahmoodabad SS, Zareei Mahmoodabadi H, Tavangar H, Yassini Ardekani SM, Vaezi AA. Family stability and conflict of spiritual beliefs and superstitions among Yazdi people in Iran: A qualitative study. World Family Medicine/Middle East Journal of Family Medicine. 2017; 15(9): 97-103. doi: 10.5742/MEWFM.2017.93108. 